\title{
Impact of Anticipated and Unanticipated Monetary Policy on Real Estate Market: A Study Based on SVAR Model
}

\author{
Chunhuan Xiao \\ School of Economics and Business Administration \\ Central China Normal University \\ Wuhan, China
}

\author{
Bo Pang \\ Wuhan University \\ Wuhan, China
}

\begin{abstract}
As a pillar industry of national economy, the real estate is closely related to people's life. The monetary policy plays an important role in regulation of real estate, which is an effective means of macroeconomic regulation. Therefore, in this paper, money supply and interest rate are selected as the measures of Chinese monetary policy, the ARIMA forecasting method is utilized to divide the monetary policy into anticipated and unanticipated, and the SVAR model are employed to analyze the impact of monetary policy on the real estate market. The results of empirical testing show that the anticipated and unanticipated monetary policies have a certain effect on the real estate market; the effect of the anticipated monetary policy is far less than the unanticipated monetary policy. There is a positive correlation between the money supply and the real estate prices, and a negatively correlation between the interest rate and the real estate prices. The effect of interest rate is greater than money supply in the regulation of real estate prices.
\end{abstract}

Keywords-anticipated monetary policy; unanticipated monetary policy; real estate price; ARIMA; SVAR

\section{INTRODUCTION}

Since 1998, Chinese real estate market has gained considerable development because of the implementation of housing commercialization reform. Due to real estate investment and total social demand show exuberant and even overheated, especially since 2003 , real estate prices are rising rapidly. In view of the rapid and excessive rise in real estate prices, the central bank of China realized that the scientific macroeconomic regulation must be used to curb this excessive trend. Since the real estate industry belongs to the capital-intensive industry, and the fluctuation of the real estate prices tend to transmit to the financial market, thereby affecting the economics [1]. Such as the Asian financial crisis of 1997 brought heavy losses to East Asian countries, the economic downturn of Japan lasted for ten years caused by real estate bubble, the subprime mortgage crisis in the US in 2008 triggered a global market turmoil. Obviously, once the real estate bubble burst, not only the development of related industries is affected, enterprises and property buyers financing chain is broken, but also lead to the entire economy into the debt deflation. Monetary policy is the most important tools for central banks to intervene in the economy [2]. The central bank of China focuses on real estate, using a series of monetary policy tools to proceed multi-aspect macroscopic readjustment and control, including the adjustment of benchmark interest rate of deposit and loan, reserve requirement ratio (RRR), refinancing and rediscount interest $r$, etc., since the real estate became the pillar industry of the national economy in $2003[3,4]$. Therefore, the analysis of the impact of monetary policy on the real estate prices not only has important practical significance, but also provides a certain reference for the central bank in the use of monetary policy.

Since the activities of people are forward-looking, the information of anticipated and the unanticipated have different effects on the economy. The anticipation has become an important factor which affects the analysis and formulation of monetary policy after the rational expectation revolution [5]. Due to the behaviors of public are based on the anticipation, the policy tools are used by monetary authorities to realize the counter-cyclical operation of monetary policy according to the anticipation formed by the historical information [6]. Although the anticipated guidance has been widely used in central banks because the importance of anticipation in monetary policy is recognized by governments, it is not comprehensive enough to analyze monetary policy from the perspective of anticipated Therefore, this paper analyzes the impact of monetary policy on the real estate market from the perspective of anticipated and unanticipated

The scholars at home and abroad have done a lot of researches on the impact of monetary policy on the real estate market, which is the hottest research topic in recent years. Kosuke Aokia et al. consider a general equilibrium model with frictions in credit markets used by households [7]. They show that this amplifies and propagates the effect of monetary policy shocks on housing investment, house prices and consumption. MarcoDel Negroa \& Christopher Otrokb use a dynamic factor model estimated on quarterly state-level data from 1986 to 2005 via Bayesian methods to disentangle the relative importance of the common component in OFHEO house price movements from local (state- or region-specific) shocks [8]. They use a VAR to 
investigate the extent to which expansionary monetary policy is responsible for this phenomenon. We find the impact of policy shocks on house prices to be small in comparison with the magnitude of recent fluctuations. Alexander Kurov find that monetary policy decisions have a significant effect on investor sentiment [9]. The effect of monetary news on sentiment depends on market conditions (bull versus bear market) and investor sentiment plays a significant role in the effect of monetary policy on the stock market. Xiaoqing EleanorXua shows that expansionary monetary policy tends to accelerate the subsequent home price growth, while restrictive monetary policy tends to decelerate the subsequent home price growth [10]. These results suggest that Chinese monetary policy actions are the key driving forces behind the change of real estate price growth in China. EleonoraGranziera \& SharonKozicki they investigate whether expectations that are not fully rational have the potential to explain the evolution of house prices and the price-to-rent ratio in the United States [11].

In summary, although there are many studies on monetary policy and housing prices at home and abroad, there is few research on the impact of monetary policy on the real estate market from the perspective of anticipated and unanticipated. Therefore, in this paper, money supply and interest rate are taken as the measures, the ARIMA is used to decompose monetary policy into anticipated and unanticipated, and then the influence of the anticipated and unanticipated monetary policy on the real estate price is analyzed by VAR model, impulse response function and variance decomposition.

\section{DECOMPOSITION OF ANTICIPATED AND UNANTICIPATED MONETARY POLICY}

Anticipation is the estimation of future economic variables before making economic decisions, which based on historical experiences and judgment of future trends. Whether monetary policy can be anticipated is directly related to monetary policy can achieve the regulation of monetary target or not. The rational anticipated school believes that monetary policy will fail under the condition of complete information because of the reasonable anticipation of the public, and only the unanticipated monetary policy have a huge impact on the economic subject. However, Keynesianism believes that both anticipated and unanticipated monetary policy is effective, but the unanticipated monetary policy has greater impact on the economy than the anticipated monetary policy.

This paper draws on the research results of related literatures at home and abroad to decompose monetary policy from the perspective of anticipated and unanticipated. There are two methods. One is the method of social investigation. That is to say to understand the public opinion on the current economic situation and anticipation of what policies have been adopted by the government. The other is to anticipate the money supply by analyzing the historical information and the time series method. Since the historical data is convenient for quantitative analysis by its availability and continuity, the second method is more feasible and easier to anticipate the true and reliable results. The current mainstream method is the ARIMA, one of the advantages of ARIMA is that a better fitting model can be selected by comparative analysis to obtain better anticipated results. The other is that its anticipation is based on the historical data of the pre- anticipated variables without considering the other economic variables, thus the correlation problem existing in the subsequent analysis is avoided. So, it is reasonable to use ARIMA model to anticipate the time series. Therefore, this method is also adopted in this paper.

The ARIMA model can be used to analyze the time series by specifying 3 parameters according to the prior study of the time series characteristics, which are autoregressive order $\left({ }^{p}\right)$, difference times $(d)$ and moving average order $\left({ }^{q}\right)$. The AIRMA can be expressed as

$$
\varphi_{p}(1-B)^{d} Z_{t}=\theta_{0}+\theta_{q}(B) \alpha_{t}
$$

Where $Z_{t}$ is original sequence, $\alpha_{t}$ denotes white noise sequence, $B$ represents backward shift operator, $B Z_{t}=Z_{t-1}$. $\varphi_{p}$ is autoregressive operator, $\varphi_{p}(B)=\left(1-\varphi_{1} B-\cdots-\varphi_{p} B^{p}\right)$, $P$ denotes autoregressive divisor. $\theta_{0}$ is parameter, $\theta_{0}=\mu\left(1-\varphi_{1}-\varphi_{2}-\cdots-\varphi_{p}\right), \quad \mu$ denotes average.

The values of anticipated monetary policy tools can be obtained by the ARIMA model, and the values of unanticipated monetary policy tools can be obtained by the deviation between the anticipated value and the actual value.

\section{A. Variable Selection and Data Processing}

There are many monetary policy tools in our country, they can be roughly divided into two types: One is the price based monetary policy tools, such as interest rate, exchange rate, etc., the other is quantitative monetary policy tools, such as reserve requirement ratio, rediscount rate and open market operation, etc.. At present, the central bank tends to use monetary supply to play the role of monetary policy in the choice of monetary policy objectives. But with the advancement of interest rate liberalization, the deepening of financial innovation and the development of the capital market, combined with the testability, controllability and correlation of the quantitative monetary policy tools, which take the money supply as the intermediary target have been gradually reduced make the effectiveness of monetary policy has been declined. It is can be seen from the actual operation, the central bank strengthens the use of interest rate policy tools continuously since 1990s. Especially after the outbreak of the subprime crisis of United States in 2007 and 2008, the central bank adjusts interest rates to macroeconomic regulation more frequently, this is enough to show that the possibility of the interest rate becoming the intermediary target of monetary policy is increasing. Therefore, the money supply and interest rate are selected in this paper as monetary policy tools to verify the impact of the anticipated and unanticipated monetary policy on the real estate market of China.

Broad money (M2) is also called quasi-money, including narrowly defined money supply, the time deposit of 
enterprise and institution and household savings. The M2 is selected to represent the quantitative money supply because it can reflect the real situation of the real economy; the data comes from the National Bureau of Statistics and the wind database.

The US federal benchmark interest rate is taken as the short-term benchmark interest rate of monetary policy by Taylor in the US [12]. But in China, interbank lending market and bond repo market are the market with the highest interest rate liberalization. Since Shibor is a kind of quoted rate which is focused by central bank, it is most likely to become the main benchmark interest rate of future interest rate liberalization in China. Therefore, the 7 day interbank lending rate is used in this study, the data comes from the official website of the Shanghai interbank lending center. The time interval is selected from January 2000 to March 2017 monthly data.

\section{B. Decomposition of Anticipated and Unanticipated Money Supply}

In order to eliminate the influence of heteroscedasticity, the logarithm of money supply is used, and the unit root testing is performed with ADF to test the stationarity of the time series. The results show that the original sequence is unstable because of the existence of unit root. Then the unit root testing of first difference sequence is given, and the results are shown in "Table I". The ADF test statistic is less than the critical value under the significant level $1 \%$ 、5\% and $10 \%$, therefore, the original hypothesis is rejected, and it is shown that there is no unit root in the first difference sequence, the time series is stationary.

TABLE I. Unit Root TeSting OF MONEY SuPPly

\begin{tabular}{|c|c|c|c|}
\hline Null Hypothesis: & M2 has a unit root & t-Statistic & Prob. \\
\hline \multicolumn{2}{|c|}{ Augmented Dickey-Fuller test statistic } & -5.881902 & 0.0000 \\
\hline \multirow{3}{*}{ Test critical values } & $1 \%$ level & -3.471987 & \\
\hline & $5 \%$ level & -2.879727 & \\
\hline & $10 \%$ level & 2.576546 & \\
\hline
\end{tabular}

The identification of ARIMA $\left({ }^{p}, d, q\right)$ model is the determination of three specific parameters, which can optimize the model. The M2 sequence of money supply is first order stationary by aforementioned tests, so it can be called integrated of order one, $d=1$, the truncation of three order is shown by sequence autocorrelation, the truncation of one order is shown from partial autocorrelation, Therefore, the initial judgment model is $\operatorname{ARIM}(1,1,3)$.

The optimal model is obtained by comparing the SC and AIC criteria. The lag length of the initial model is increased moderately, according to the parsimony principle, we set the maximum value of a and $\mathrm{c}$ are 3 , and the regression of model is shown in "Table II".
TABLE II. COMPARISON BETWEEN AIC AND SC

\begin{tabular}{|l|l|l|l|}
\hline \multicolumn{1}{|c|}{$p$} & $q$ & \multicolumn{1}{|c|}{ AIC } & \multicolumn{1}{c|}{ SC } \\
\hline 1 & 1 & -5.30 & -5.25 \\
\hline 1 & 2 & -5.36 & -5.29 \\
\hline 1 & 3 & -5.44 & -5.34 \\
\hline 2 & 1 & -5.31 & -5.23 \\
\hline 2 & 2 & -5.40 & -5.30 \\
\hline 2 & 3 & -5.39 & -5.29 \\
\hline 3 & 1 & -5.38 & -5.31 \\
\hline 3 & 2 & -5.36 & -5.32 \\
\hline 3 & 3 & -5.41 & -5.39 \\
\hline
\end{tabular}

It can be seen that AIC and SC are minimum when $p=1$ and $q=3$. Overall consideration, the ARIMA $(1,1,3)$ fitted the best, the coefficients are significant, and the residual sequence is uncorrelated, the expression can be obtained as

$$
\begin{aligned}
d m 2_{t}= & 0.0159-0.00421 d m 2_{t-1}+0.7204 \varepsilon_{t-1} \\
& +0.7350 \varepsilon_{t-2}+0.5758 \varepsilon_{t-3}
\end{aligned}
$$

According to the above expression, the money supply from January 2000 to March 2017 is anticipated, and then the unanticipated money supply can be obtained by the difference between the actual value and anticipated value of money supply. "Fig. $1 "$ is the time series after data processing, representing the actual money supply and the expected money supply respectively.

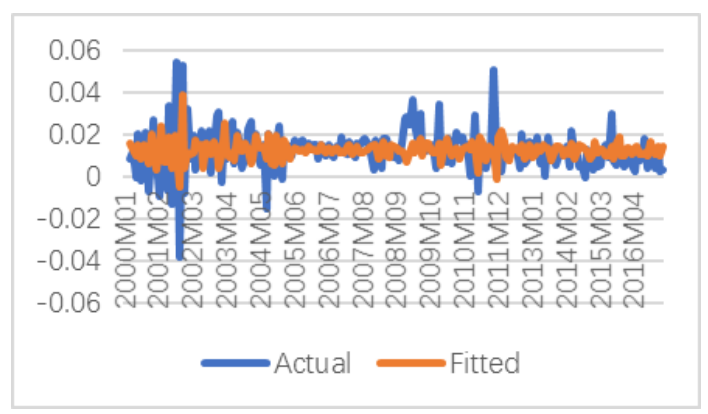

Fig. 1. Actual value and anticipated value of money supply.

\section{Decomposition of Anticipated and Unanticipated Interest Rate}

In order to eliminate the influence of heteroscedasticity, the logarithm of time series is used, and the unit root test is performed with ADF to test the stationarity of the time series. The results show in "Table III", that he critical values are $3.458845,-2.873974$ and -2.573472 , ADF is -4.856692 . The ADF test statistic is less than the critical value, therefore, the original hypothesis is rejected, and it is shown that there is no unit root in the time series, it is stationary.

TABLE III. UNIT ROOT TEST OF INTEREST RATE

\begin{tabular}{|c|l|l|c|}
\hline \multicolumn{2}{|c|}{ Null Hypothesis: R has a unit root } & t-Statistic & Prob. \\
\hline \multicolumn{2}{|c|}{ Augmented Dickey-Fuller test statistic } & -4.856692 & 0.0001 \\
\hline \multirow{3}{*}{ Test critical values } & $1 \%$ level & -3.458845 & \\
\cline { 2 - 4 } & $5 \%$ level & -2.873974 & \\
\cline { 2 - 4 } & $10 \%$ level & -2.573472 & \\
\hline
\end{tabular}


The identification of model is identified by auto correlative function and partial correlation. The original time series of R shows "tailing" phenomenon, while PACF exhibits 2 order truncations, so the initial judgment model is AR (2).

The optimal model is obtained by comparing the SC and AIC criteria. The lag length of the initial model increases, the regression of model is shown in "Table IV".

TABLE IV. COMPARISON OF AIC AND SC

\begin{tabular}{|c|c|c|c|c|}
\hline$q$ & $\mathbf{1}$ & $\mathbf{2}$ & $\mathbf{3}$ & $\mathbf{4}$ \\
\hline $\boldsymbol{A I C}$ & -7.57 & -7.57 & -7.57 & -7.58 \\
\hline $\boldsymbol{S C}$ & -7.54 & -7.52 & -7.50 & -7.50 \\
\hline
\end{tabular}

It can be seen in Table IV, SC and AIC are minimum when $q=1$ and $q=4$. The AR(1) Model is chosen, and the coefficients are significant, the residual sequence is uncorrelated, the expression can be obtained as

$$
\ln r_{t}=-3.67+0.88 \ln r_{t-1}+\varepsilon_{t}
$$

According to the above expression, the 7-day interbank lending rate from January 2000 to March 2017 is anticipated, and then the unanticipated money supply can be obtained by the difference between the actual value and anticipated value of interest rate. "Fig. 2" is the actual value of interest rates and anticipated values.

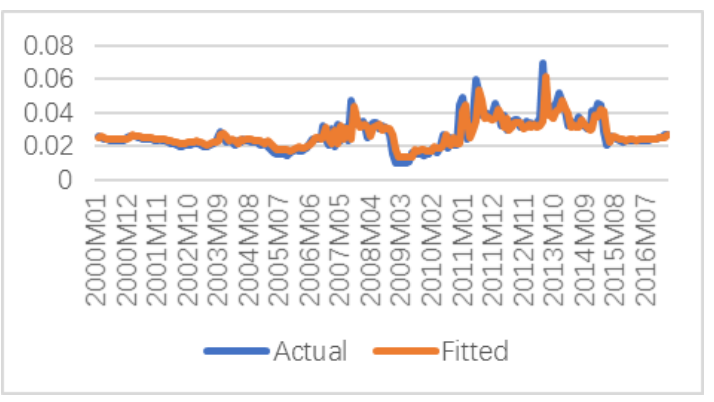

Fig. 2. Actual value and anticipated value of interest rate.

\section{EMPIRICAL TESTING OF THE IMPACT OF ANTICIPATED AND UNANTICIPATED MONETARY POLICY ON REAL ESTATE MARKET}

\section{A. Empirical Testing of the Impact of Anticipated Monetary Policy on Real Estate Market}

There are many methods to select the real estate price data, but they are imperfection. According to the availability and continuity of data, the average sales price of commercial housing is taken as a representative variable of house prices in this paper, which is the quotient of commercial housing sales volume divided by sales area of commercial housing. The price of real estate is greatly influenced by season, and the change of season will lead to regular change of time series. In order to reflect the essence of macroeconomic phenomena more accurately, it is necessary to eliminate and adjust the seasonal variation factors. After adjustment of season by X12 method, we obtain the logarithm to eliminate the influence of heteroscedasticity. LNHP is the time series of processed the real estate price, and then carry out the unit root test. The results show that the LNHP sequence is stationary sequence, as shown in Table V. The data comes from the official website of the National Bureau of Statistics.

TABLE V. UNIT RoOT TESTING OF LNHP

\begin{tabular}{|c|l|c|c|}
\hline \multicolumn{2}{|c|}{ Null Hypothesis: LNHP has a unit root } & t-Statistic & Prob. \\
\hline \multicolumn{2}{|c|}{ Augmented Dickey-Fuller test statistic } & -10.06727 & 0.0000 \\
\hline \multirow{3}{*}{ Test critical values } & $1 \%$ level & -3.462737 & \\
\cline { 2 - 4 } & $5 \%$ level & -2.875680 & \\
\cline { 2 - 4 } & $10 \%$ level & -2.574385 & \\
\hline
\end{tabular}

Since the VAR cannot describe the contemporaneous correlation of variables, the SVAR is used to explain the dynamic relationship of variables because it can set contemporaneous correlation by economic theory and reality. The right side of the VAR model does not contain the current value of the endogenous variable, it is unexplained because the current relation hidden in the related structure of the error term. The VAR is improved by Blanchard and other scholars, a SVAR model is proposed. They try to join in the structural impulse constraint in model to solve the problem of information recognition. The relationship between SVAR and its corresponding simplified VAR as follow:

$$
A \varepsilon_{t}=B u_{t}
$$

Where $u_{t}$ and $\varepsilon_{t}$ denote structural impulse and compound impulse, respectively. Generally speaking, the SVAR model with $n$ endogenous variables requires the number of constrains at least is $n(n-1) / 2$. To ensure that the model can be identified, it is necessary to impose constraints on the contemporaneous relation matrix $A$, and then the relation of other parameters can be obtained.

Firstly, the lag order of each variable should be determined, and it is necessary to consider not only the integrity of the dynamic feature of the SVAR model, but also the influence of the freedom by lag order. The lag order of the SVAR model is determined by the lag order of the corresponding VAR model, The value of LR, FPE, AIC, SC and HQ are given by Table VI, The lag period corresponded to "*" is the optimal lag order under the corresponding test criterion. It can be observed that 3 is the optimal lag order by FPE and AIC criterions.

\section{TABLE VI. LAG ORDER TESTING}

\begin{tabular}{|c|c|l|l|l|l|c|}
\hline Lag & LogL & \multicolumn{1}{|c|}{ LR } & \multicolumn{1}{|c|}{ FPE } & \multicolumn{1}{c|}{ AIC } & SC & HQ \\
\hline $\boldsymbol{0}$ & 299.8335 & NA & $9.56 \mathrm{e}-06$ & -3.044446 & -2.994092 & -3.024058 \\
\hline $\boldsymbol{1}$ & 1035.988 & 1442.108 & $5.51 \mathrm{e}-09$ & -10.50244 & $-10.30102 *$ & -10.42089 \\
\hline $\boldsymbol{2}$ & 1056.509 & 39.56835 & $4.90 \mathrm{e}-09$ & -10.62060 & -10.26813 & $-10.47789 *$ \\
\hline $\mathbf{3}$ & 1065.942 & 17.89872 & $4.88 \mathrm{e}-09 *$ & $-10.62504 *$ & -10.12151 & -10.42117 \\
\hline $\mathbf{4}$ & 1069.464 & 6.575145 & $5.16 \mathrm{e}-09$ & -10.56886 & -9.914264 & -10.30382 \\
\hline $\mathbf{5}$ & 1082.143 & 23.27765 & $4.97 \mathrm{e}-09$ & -10.60660 & -9.800938 & -10.28040 \\
\hline
\end{tabular}

The stability test is the criterion to test the rationality of the theory, and it is also the precondition of impulse response analysis. As shown in "Fig. 3", the blue points denote the modulus of reciprocal of AR roots, if these points fall within the unit circle, which means that the VAR model is stationary, otherwise the VAR model is not stationary. It is 
easily observed that all points are fall in the unit circle, so that the VAR is stationary, and the next step can be studied.

Inverse Roots of AR Characteristic Polynomial

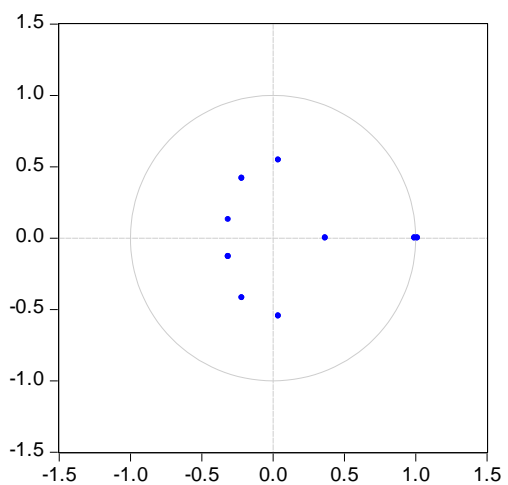

Fig. 3. AR diagram of 3 phases with lag.

The IRF analysis is the dynamic effect of the impact on the current of endogenous variables and future values after the standard deviation impulse from insystem or outsystem on the random error term. The IRF can be used to analyze the influence of the anticipated money supply and anticipated interest rate shocks on the real estate price. The test results are shown in "Fig. 4".
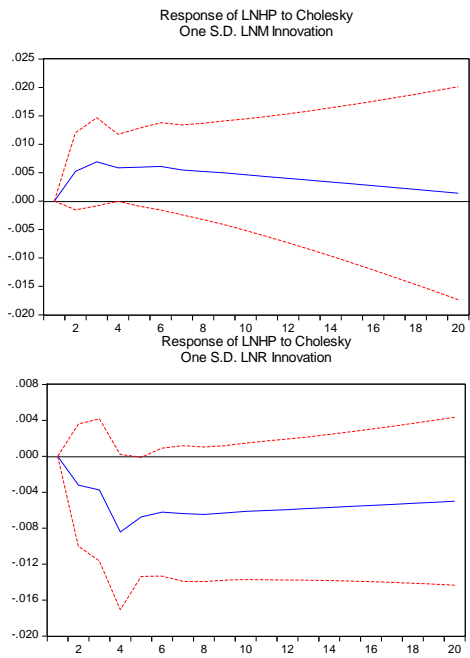

Fig. 4. Impulse response function of anticipated monetary policy to real estate prices.

In the "Fig. 4", the horizontal axis represents the lag order, and the longitudinal axis indicates the response degree of the real estate price to a standard deviation impulse. After a positive impact on the anticipated money supply, house prices begin to rise from the first phase and reach the highest value 0.063 in the third phase. After a positive impact on the anticipated interest rate, house prices begin to decrease rapidly from the first phase, and reach the minimum value0.008 in the fourth phase. With the lag of time, house prices began to rise slowly. From the eighth phase, it gradually tends to be stable and maintains at a certain negative correlation level. Comparatively speaking, the anticipated interest rate has a greater impact on house prices than the money supply.

TABLE VII. VARIANCE DECOMPOSITION

\begin{tabular}{|c|c|c|c|c|}
\hline Period & S.E. & LNHP & LNM & LNR \\
\hline $\boldsymbol{1}$ & 0.047601 & 100.0000 & 0.000000 & 0.000000 \\
\hline $\mathbf{5}$ & 0.079822 & 95.68203 & 2.138377 & 2.179597 \\
\hline $\mathbf{1 0}$ & 0.109396 & 94.94566 & 2.264386 & 2.789953 \\
\hline $\mathbf{1 5}$ & 0.132769 & 95.23102 & 1.926255 & 2.842728 \\
\hline $\mathbf{2 0}$ & 0.152952 & 95.71484 & 1.556407 & 2.728755 \\
\hline
\end{tabular}

It can be observed in Table VII that the house prices have a greater impact on itself. By the twentieth phase, the impact of house prices on itself is about $95 \%$. The contribution of the anticipated money supply and the anticipated interest rate is maintained at around $2 \%$, and the anticipated impact of interest rate on house prices slightly stronger than anticipated money supply, but the effects are not significant.

\section{B. Empirical Testing of the Impact of Unanticipated Monetary Policy on the Real Estate Market}

Similarly, the lag order is determined by VAR, and it can be known in "Table VIII", the lag order is 5.

TABLE VIII. LAG ORDER TESTING

\begin{tabular}{|c|c|l|l|l|l|c|}
\hline Lag & LogL & LR & FPE & AIC & SC & HQ \\
\hline $\boldsymbol{0}$ & -3.522673 & NA & 0.000215 & 0.066899 & 0.117253 & 0.087287 \\
\hline $\mathbf{1}$ & 1033.824 & 2032.135 & $5.64 \mathrm{e}-09$ & -10.48024 & $-10.27883^{*}$ & -10.39869 \\
\hline $\mathbf{2}$ & 1057.048 & 44.78038 & $4.87 \mathrm{e}-09$ & -10.62613 & -10.27365 & $-10.48342 *$ \\
\hline $\mathbf{3}$ & 1064.091 & 13.36507 & $4.97 \mathrm{e}-09$ & -10.60607 & -10.10253 & -10.40219 \\
\hline $\mathbf{4}$ & 1075.371 & 21.05604 & $4.86 \mathrm{e}-09$ & -10.62945 & -9.974850 & -10.36441 \\
\hline $\mathbf{5}$ & 1086.247 & $19.96606^{*}$ & $4.77 \mathrm{e}-09 *$ & $-10.64868^{*}$ & -9.843024 & -10.32248 \\
\hline \multicolumn{7}{c}{ Inverse Roots of AR Characteristic Polynomial } \\
\hline
\end{tabular}

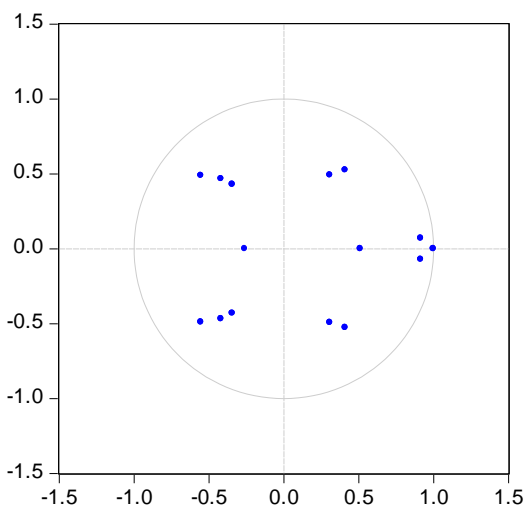

Fig. 5. AR diagram of 5 phases with lag

It can be observed in "Fig. 5", all unit roots of the VAR model fall within the unit circle, so we can conclude that the VAR model is stable. Then the impulse response function (IRF) and variance decomposition analysis can be carried out. 

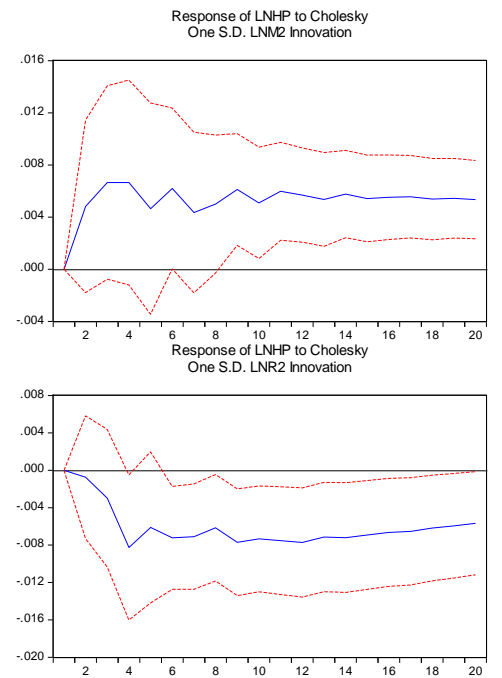

Fig. 6. Impulse response function of unanticipated monetary policy to house prices.

In the "Fig. 6", it can be seen that when the anticipated money supply has a positive impact, house prices begin to rise from the first phase, and reached the maximum value of 0.0067 in third and fourth phase, Then the house prices begin go fluctuate, as the time goes by, the fluctuation decreases, housing prices remained at a certain level until the fifteenth phase. It can be concluded from the figure that the impact of unanticipated money supply on house prices is greater than the anticipated money supply. When the anticipated money supply has a positive impact, the house prices begin to decline from the first phase, and reached the lowest value of 0.0067 in third phase, then the house prices begin to fluctuate, and drop to a certain point at ninth phase, as the time goes by, the house price is stable at a certain level. Therefore, the effect of unanticipated interest rate over anticipated interest rate on house prices fluctuation.

TABLE IX. VARIANCE DECOMPOSITION

\begin{tabular}{|c|c|c|c|c|}
\hline Period & S.E. & LNHP & LNM2 & LNR2 \\
\hline $\boldsymbol{1}$ & 0.045213 & 100.0000 & 0.000000 & 0.000000 \\
\hline $\mathbf{5}$ & 0.059781 & 93.05359 & 3.730663 & 3.215750 \\
\hline $\mathbf{1 0}$ & 0.064904 & 84.62771 & 6.618977 & 8.753316 \\
\hline $\mathbf{1 5}$ & 0.068175 & 76.89089 & 9.427849 & 13.68126 \\
\hline $\mathbf{2 0}$ & 0.070788 & 71.76290 & 11.70651 & 16.53059 \\
\hline
\end{tabular}

It can be observed from the "Table IX", from the first phase, the variance of house prices variance contributes $100 \%$ to itself, and the contribution of the other two economic variables is 0 . As the number of phase increases, the variance of house prices variation is gradually reduced in the part of explanation by itself, while the part of explanation by unanticipated money supply and the unanticipated interest rate gradually increases. In the twentieth phase, about $11.7 \%$ of the variance in house prices variation is explained by unanticipated money supply changes, and $16.5 \%$ of the variance in housing price variation is explained by unanticipated interest rate changes.

\section{CONCLUSION}

In this paper, we choose the money supply and interest rate as the measurement indexes, which are representative monetary policy tool of quantity type and price type, respectively. The ARIMA anticipation method is used to decompose the monetary policy into anticipated and unanticipated, and then based on the SVAR model, impulse response function and variance decomposition method to analyze the influence of monetary policy of anticipated and unanticipated monetary policy on the real estate price. The conclusions are as follows:

The anticipated and unanticipated monetary policy has a certain impact on the real estate market, and the effect of the anticipated monetary policy is less than the effect of the unanticipated monetary policy. It can be seen from impulse response function and variance decomposition, the explanation of house prices by anticipated monetary policy is $4 \%$, the explanation of house prices by unanticipated monetary policy is $28 \%$. Due to the anticipated monetary policy has played a role before it has been implemented, and it has little impact on house prices after the implementation of the policy. The central bank should fully consider the impact of public anticipations on the real estate market when making monetary policy, and guide the public to form reasonable anticipations to enhance the effectiveness of monetary policy.

There is a positive correlation between money supply and real estate prices, and there is a continuous negative correlation between interest rate and real estate prices. In the regulation of real estate prices, the effect of interest rate is greater than that of money supply.

The monetary policy formulated by the Central Bank of China is transmitted to the market mainly through the commercial banks. The central bank adjusts the money supply by monetary policy tool of statutory reserve requirements, rediscount rates, and open market operations, thereby affecting the lending capacity of banks. Real estate is a capital-intensive industry, and its supply and demand are inseparable from financial support. The main source of funds for the project is self-financing and bank credit, and most of the funds mainly rely on bank credit, so the tightness of bank credit has a direct impact on the development of the real estate market. The money supply has direct influence on the scale of bank credit supply, real estate development projects mainly rely on bank credit funds, once the scale of credit funds changes, the scale of real estate market development fund and real estate market supply will changes, and then lead to real estate price changes.

Since 1996, China has liberalized the interbank lending market, and the interbank lending rate gradually reflects the market interest rate level, and the interest rate regulation effect on the economy is also gradually emerging. The level of interest rate affects the cost of real estate investment, but also affects the public demand for housing, thereby affecting housing prices. Therefore, compared with the money supply, the interest rate effect is an important channel for monetary policy to affect the real estate prices. 


\section{REFERENCES}

[1] Gholipour H F, Al-mulali U, Mohammed A H. Foreign investments in real estate, economic growth and property prices: evidence from OECD countries [J]. Journal of Economic Policy Reform, 2014, 17(1): $33-45$.

[2] Cúrdia V, Woodford M. Credit frictions and optimal monetary policy [J]. Journal of Monetary Economics, 2016, 84: 30-65.

[3] Lowry G V, Shaw S, Kim C S, et al. Macroscopic and microscopic observations of particle-facilitated mercury transport from New Idria and Sulphur Bank mercury mine tailings [J]. Environmental Science \& Technology, 2004, 38(19): 5101-5111.

[4] Robbins L L, Yates K K, Shinn G, et al. Whitings on the Great Bahama Bank: a microscopic solution to a macroscopic mystery[J]. Bahamas Journal of Science, 1996, 4(1): 2-7.

[5] D'Amico S, King T B. What does anticipated monetary policy do? [J]. 2015.

[6] Verona F, Martins M M F, Drumond I. (Un) anticipated monetary policy in a DSGE model with a shadow banking system [J]. 2013.

[7] Aoki K, Proudman J, Vlieghe G. House prices, consumption, and monetary policy: a financial accelerator approach [J]. Journal of financial intermediation, 2004, 13(4): 414-435.

[8] Del Negro M, Otrok C. 99 Luftballons: Monetary policy and the house price boom across US states [J]. Journal of Monetary Economics, 2007, 54(7): 1962-1985.

[9] Kurov A. Investor sentiment and the stock market's reaction to monetary policy [J]. Journal of Banking \& Finance, 2010, 34(1): 139149.

[10] Xu X E, Chen T. The effect of monetary policy on real estate price growth in China [J]. Pacific-Basin Finance Journal, 2012, 20(1): 6277.

[11] Granziera E, Kozicki S. House price dynamics: Fundamentals and expectations [J]. Journal of Economic Dynamics and Control, 2015, 60: $152-165$.

[12] Taylor J B. Discretion versus policy rules in practice [C]//CarnegieRochester conference series on public policy. North-Holland, 1993, 39: $195-214$. 